\title{
Biospecimen Science of Blood for Peripheral Blood Mononuclear Cell (PBMC) Functional Applications
}

\author{
Fay Betsou $^{1} \cdot$ Amelie Gaignaux $^{1} \cdot$ Wim Ammerlaan ${ }^{1} \cdot$ Philip J. Norris $^{2} \cdot$ Mars Stone $^{2}$
}

Published online: 11 May 2019

(C) The Author(s) 2019

\begin{abstract}
Purpose of Review Peripheral blood mononuclear cells (PBMCs) are used in a wide variety of preclinical assays. Preanalytical variations can have a devastating impact on the results. In this review, we list critical preanalytical factors for PBMC-based assays to develop awareness and orientation to the types of sample preparation and storage that one may consider employing.

Recent Findings Critical factors during blood collection are the blood collection tube and anticoagulant, possible stabilizer used, and the pre-isolation blood storage temperature and time. During PBMC isolation, critical factors are the isolation method, density gradient or magnetic sorting, use of barrier, possible RBC lysis, and centrifuge type. During cryopreservation, attention is needed for the cryomedium type and temperature, freezing device and program, cell concentration, and the long-term storage temperature. During the thawing process, the thawing procedure/device used and wash medium temperature are critical.

Summary To avoid biased results in PBMC assays, these critical preanalytical factors must be standardized and/or documented. Additionally, participation in external quality assurance programs is strongly recommended.
\end{abstract}

Keywords PBMC $\cdot$ Human blood $\cdot$ Preanalytics $\cdot$ Functional assays $\cdot$ Cryopreservation $\cdot$ Quality control

\section{Introduction}

Peripheral blood mononuclear cells (PBMCs), including monocytes and lymphocytes, are often isolated from

This article is part of the Topical Collection on Biospecimens Science and Evidence-Based Standards for Precision Medicine

Fay Betsou

Fay.Betsou@ibbl.lu

Amelie Gaignaux

Amelie.Gaignaux@ibbl.lu

Wim Ammerlaan

Wim.Ammerlaan@ibbl.lu

Philip J. Norris

PNorris@ vitalant.org

Mars Stone

MStone@ vitalant.org

IBBL, 1 rue Louis Rech, L3555, Dudelange, Luxembourg

2 Vitalant Research Institute, 270 Masonic Ave, San Francisco, CA 94118, USA anticoagulated blood for use in preclinical and clinical research. They may be used for further processing, such as immunomagnetic bead-based sorting of specific cell subpopulations, establishment of lymphoblastoid cell lines (LCL) [1], or extraction of nucleic acids. Endpoint use of either whole or subprocessed (i.e., sorted, transformed) PBMCs is always analytical and feeds into two assay categories, (i) assays not requiring viable cells, such as DNA-based genetic analysis and RNA-based gene expression analyses, and (ii) assays requiring intact or viable cells, such as immunophenotyping and functional assays. Functional assays include radiosensitivity assays on LCLs [2], chromosome-based analysis (chromosome aberration assays) for detection of genotoxicity [3], monitoring of autophagy activity [4], chemotaxis assays [5], natural killer (NK) cytotoxicity assays [6], leukocyte recruitment and adhesive interactions with endothelial cells, suppression assays [7], antigen-specific response assays such as lymphocyte proliferation assays, intracellular cytokine staining (ICS), and enzyme-linked immunospot (ELISPOT) assays. ELISPOT is important for vaccine studies, enabling quantification of IgG-secreting B cells and the assessment of memory $\mathrm{B}$ cell activity. Also, the relative frequencies and cytokine signatures of antigen-specific $\mathrm{T}$ cells are considered surrogate 
biomarkers of the T cell immunity in vivo, while HLA-peptide multimer staining assays [8] are applied in monitoring antigen-specific $\mathrm{T}$ cell responses after immunotherapy.

Most of these assays are performed in non-regulated preclinical research laboratories. However, at least one regulated functional application has recently emerged: the monocyte activation test (MAT) for detection and quantification of pyrogenic contamination in pharmaceuticals [9]. Similarly, PBMCs are used to detect unwanted intrinsic proinflammatory activities of different biological therapeutics through cytokine (IL-6, IL-1 $\beta$, TNF- $\alpha$ ) release [10].

For DNA- and RNA-based assays, cells do not need to be viable; rather, immediate stabilization after isolation in an appropriate nucleic acid (NA) stabilizer and freezing until NA extraction is optimal. For immunophenotyping, cells need to be intact, and they need to be viable for all functional assays. Functional analyses may be performed either on freshly isolated cells or on cells after cryopreservation.

Preanalytic characterization and quality control (QC) preceding the above downstream applications have received only very limited attention until now. Standard characterization and QC assays before cryopreservation include (i) cell enumeration in order to optimize the cell concentration in the cryotubes and (ii) cell viability and early apoptosis measurement via impedance-based, trypan blue-based, or flow cytometricbased methods in order to assess the cell health before (prefreeze) and/or after (post-thaw) cryopreservation [11]. ELISPOT assays are usually an endpoint in themselves, but may also be performed as QC to assess the functional status of the cells, especially after cryopreservation. It has been shown that viability $\geq 70-75 \%$ corresponds to a critical QC threshold in the scope of consistent proliferative responses of lymphocytes $[12,13]$. However, in the regulated context of the MAT, the acceptable viability threshold is $95 \%$ [10]. Early apoptosis $<20 \%$ has been shown to be an acceptable QC threshold to effectively measure response to different antigenic stimulation [14]. Different preanalytical parameters may affect the viability/apoptosis status of the PBMCs, including blood precentrifugation time and temperature and suboptimal freezing/thawing. A QC assay which allows the specific assessment of the precentrifugation delay of the blood specimen from which the PBMCs have been isolated has recently been described [15•], which is based on the ratio of gene expression of the IL8 and EDEM3 genes ("PBMC preanalytical score").

The scope of this article mainly covers the impact of preanalytics on PBMC functional endpoints, and does not cover QC for molecular (DNA- and RNA-based) analyses). The definition of "preanalytics" corresponds to a "processing method," including all steps and operations occurring between the moment of blood collection and the moment PBMCs are delivered to the analytical laboratory. In this sense, the interval between blood collection and centrifugation is a preanalytical factor, but the time during which isolated PBMCs are cultured before measuring cytotoxicity or before monitoring antigenspecific $T$ cell responses [16] is considered as part of the analytical workflow (Fig. 1).

\section{Critical Preanalytical Variables}

The "critical preanalytical variables" are the critical factors in the PBMC processing method that have a significant impact on the quality of the produced PBMCs. Quality attributes are more or less "sensitive," with cytotoxicity assays or antigenspecific proliferation assays being more sensitive to the insults of cryopreservation than recovery and viability assays.

\section{Anticoagulants/Blood Collection Tubes}

Different anticoagulants and blood collection tubes can be used for PBMC isolation. When comparing EDTA, ACD, and heparin with a precentrifugation delay of up to $24 \mathrm{~h}$, for PBMC recovery and viability, the differences were not significant. The differences were, however, significant for ELISPOT, with heparin being the most robust to the 24-h delay [17]. EDTA is not the preferred anticoagulant for PBMC isolation for some applications. It has been shown that cytokine-induced killer (CIK) cell proliferation is ineffective when blood has been collected in EDTA [18], that NK cytotoxicity is dramatically decreased in EDTA [19], and that EDTA increases proinflammatory cytokine mRNAs, and may therefore introduce bias in downstream analyses [20]. Citrate can be used in ACD-A (BD, ref 366645), ACD-B (BD, ref 367756), or CPT citrate (BD, ref 362782) tubes. Heparin can be used in standard Li heparin tubes (BD, ref 367526) or CPT heparin tubes (BD, ref 362780), though heparin has been shown to interfere with nucleic acid amplification assays [21], which may be reversible through treatment of samples with heparinase [22].

Heparin or ACD anticoagulants were found to be better than EDTA for PBMC preservation for downstream $B$ and $T$ cell analysis [23]. Blood collection in ACD tubes better stabilizes lymphocytes for establishment of LCLs, with EpsteinBarr virus (EBV) transformation being effective 1 week after blood collection, in contrast to blood collected in EDTA where EBV transformation is effective only up to $24 \mathrm{~h}$ after collection (Betsou, IBBL, unpublished).

When heparin and ACD-A were compared with EDTA, it was found that the relative frequency of CD14+ monocytes was higher with EDTA, although the relative frequencies of monocyte subsets were not altered by the anticoagulant used [24•]. Complete filling of the blood collection tube also impacted the relative amount of monocytes, as it perturbed the optimal blood to anticoagulant ratio. A previous study had shown that the mean channel fluorescence intensity of 
Fig. 1 Examples of workflows showing the distinction between processing and analytical methods. PBMCs or PBMC subpopulations are the output of the processing methods (blue) and the input of the analytical methods (orange). The red line shows the scope of this review article, which includes functional analyses on viable cells

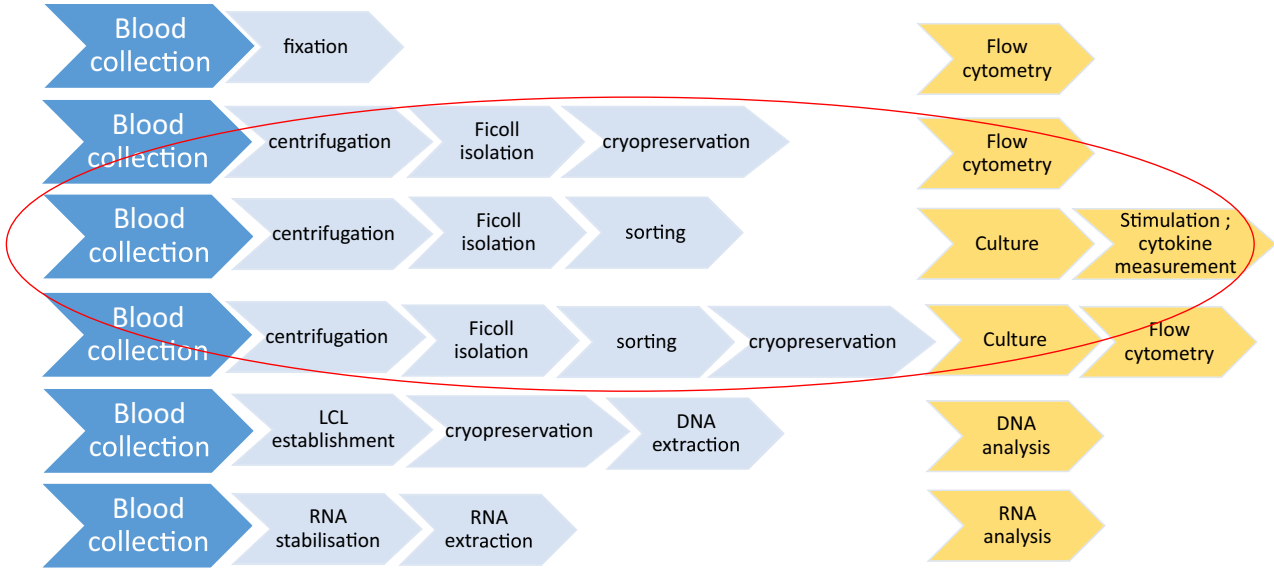

membrane CD14 on monocytes in blood samples collected with heparin was higher than in blood collected with EDTA or citrate [25]. For NK cytotoxicity assays, heparin is also preferable to EDTA [19].

CPT citrate and CPT heparin tubes are particularly convenient because they allow PBMC isolation in significantly shorter time as compared to a Ficoll-based procedure (see below). When these two types of tubes are compared with a 24-h precentrifugation delay at RT, in terms of cell subpopulation composition, there is a higher probability of granulocyte (CD15+) contamination in the CPT citrate tubes (Ammerlaan, IBBL, unpublished). In the scope of proliferation-based assays, the odds of obtaining a response were higher in PBMCs collected in citrate CPT than in heparin or ACD tubes, with the exception of one antigen [26]. Putting together all the above data, CPT heparin tubes are a good choice for cryopreservation of cells for functional assays.

\section{Use of Stabilizers}

Cells are not viable after NA or protein stabilization. Very briefly, blood collection tubes (BCT) may contain NA stabilizers that either lyse the cells and inhibit nucleases (e.g., Paxgene RNA BCT) or fix the cells without lysing them (e.g., Paxgene ccfDNA BCT). Such stabilization is critical for downstream gene expression analyses.

The use of cell surface protein stabilizers facilitates downstream immunophenotypic analyses, especially for epitopes which are known to be sensitive to preanalytical conditions. The Proteomic Stabilizer (Smart Tube Inc.) has recently been used to study immune activation and monocyte phosphoproteins by CyTOF [27•]. Although granulocytes are not in the main scope of this article, it has to be noted that preservation of cell surface antigens of granulocytes requires stabilization [28]. The use of a special stabilizer which prevents granulocyte contamination of the PBMC layer is described in the next paragraph.

\section{Delays Between Collection and Processing}

The interval between collection and processing is the most critical parameter affecting the performance of lymphocytes in immunological assays. Granulocytes can become activated with longer blood storage time, their density may decrease, and they may thus contaminate the enriched PBMC fraction [29]. Granulocytes are known to become activated in some diseases, such as cancer [30], and release pre-stored granules, which may cause oxidative stress to lymphocytes with negative consequences in viability and cytokine release ability. The presence of granulocytes in the PBMC layer may also create interference and non-specific background in different downstream assays. To overcome this preanalytical challenge, cellspecific antibody-based reagents have been commercialized (T Cell Xtend ${ }^{\circledR}$ by Oxford Immunotec) which cross-link granulocytes to red blood cells (RBCs), thus increasing their density and inducing their pelleting through density gradients. Restoration of the relative percentages of lymphocytes and granulocytes after 24- and 48-h precentrifugation delays in heparin tubes with the T Cell Xtend ${ }^{\circledR}$ has been demonstrated [31]. Another way to prevent granulocyte contamination is by diluting the blood with PBS upon collection [29].

A significant reduction in IFN- $\gamma$-secreting cells, measured by either ELISPOT or ICS, has been observed with precentrifugation delay, independently from anticoagulant, and especially for low responding samples, unless CPT is used for the isolation [17]. Similar differences between immediate and 24-h processing have been found for lymphocyte proliferation assays (LPA) [26, 32], but also for RNA extraction, yield, and integrity [33].

In addition to time to processing, storage temperature between blood collection and processing is critical. Olson et al. studied the impact of time/ambient temperature combinations on recovery, viability, and IFN- $\gamma$ secretion in ELISPOT, for temperatures between 15 and $40{ }^{\circ} \mathrm{C}$. They found that heparinized blood exposure to $15^{\circ} \mathrm{C}$ or $40{ }^{\circ} \mathrm{C}$ for more than $8 \mathrm{~h}$ negatively impacted post-thaw viability and immune function 
of cells and recommended shipment of blood at $22-30{ }^{\circ} \mathrm{C}$ and use of prewarmed gel packs when shipping in the winter [34].

Delays between blood collection and processing of more than $8 \mathrm{~h}$ induced a significant reduction in PBMC chemokine receptor (CCR4, CCR7) expression and decreased the ability of NK cells to degranulate (CD107 $\alpha$ expression) and secrete cytokines (IFN- $\gamma$, TNF- $\alpha$ ) [35]. Surprising data on the optimal conditions between blood collection and processing have been reported in the scope of NK cytotoxicity assays, for which overnight storage of ACD blood at $4{ }^{\circ} \mathrm{C}$ avoided loss of NK cytotoxicity, associated with an increased NK fraction [36].

\section{a PBMC viability after pre-centrifugation delay, before cryopreservation}

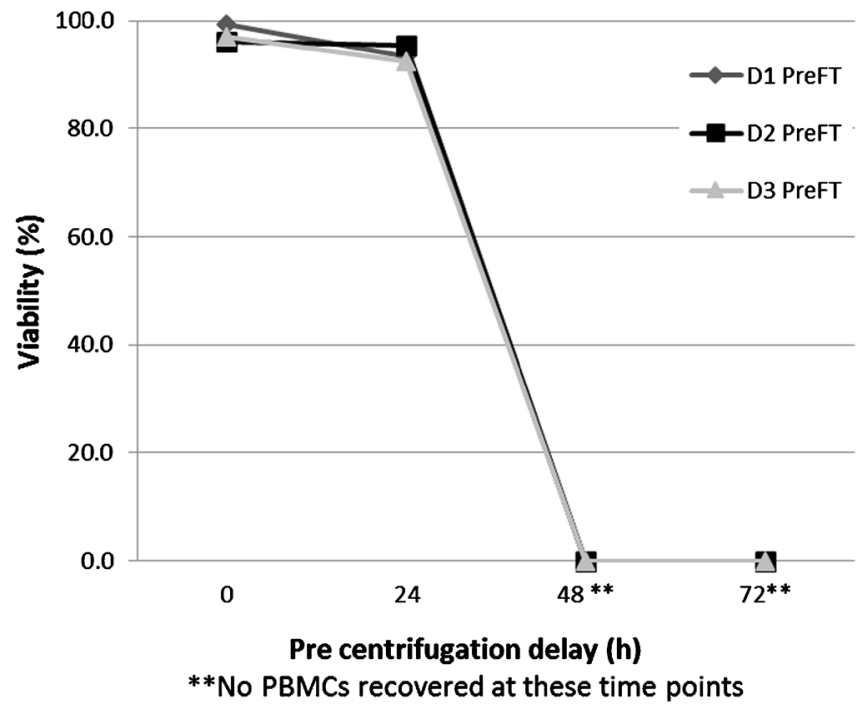

\section{PBMC Viability after post centrifugation delay, before cryopreservation}

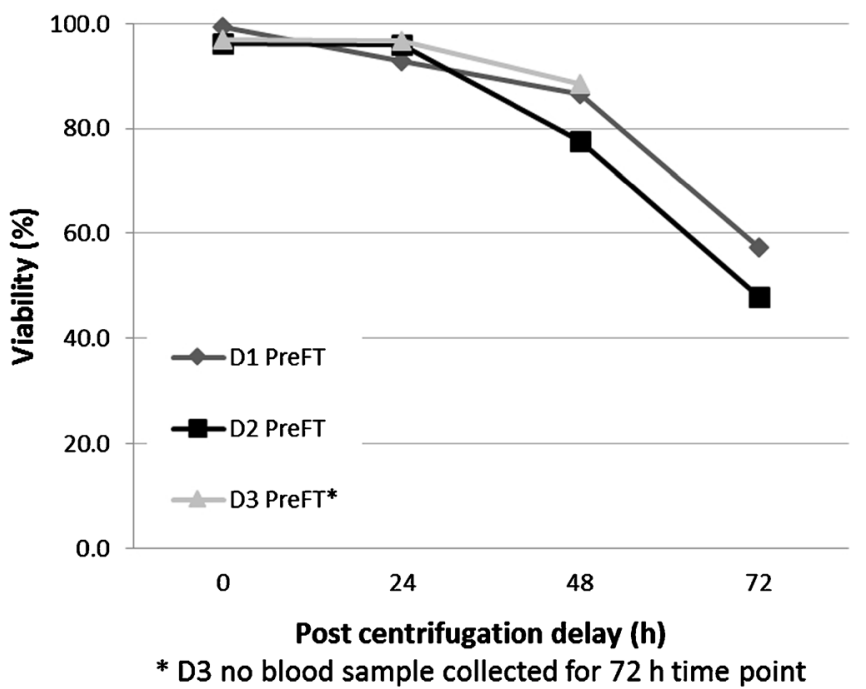

When using CPT, if not processed on site, the filled tubes must be shipped to the processing laboratory at RT prior to centrifugation. They should not be centrifuged on site, then shipped. Indeed, a post-centrifugation delay of 48 or $72 \mathrm{~h}$ causes a significant loss of viability before cryopreservation and an even more dramatic loss of viability after cryopreservation. A precentrifugation delay of up to $24 \mathrm{~h}$ does not significantly impact viability, cell subpopulation composition, and ELISPOT responses; however, at $48 \mathrm{~h}$, the PBMCs cannot effectively be separated from the RBCs (Ammerlaan, IBBL, unpublished) (Fig. 2).

\section{b PBMC viability after pre-centrifugation delay,} after cryopreservation

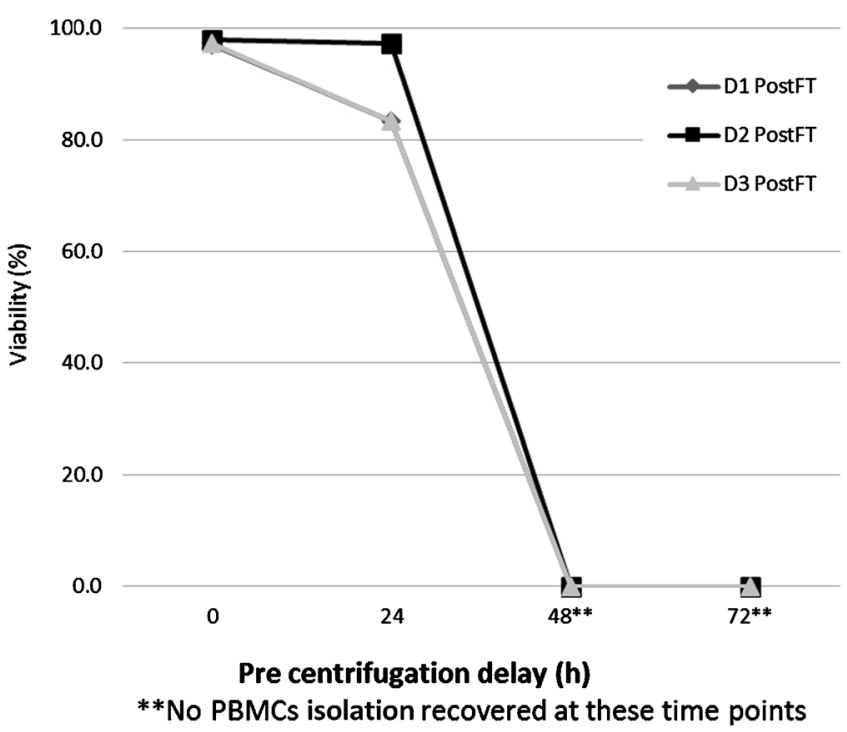

\section{d PBMC Viability after post centrifugation delay, after cryopreservation}

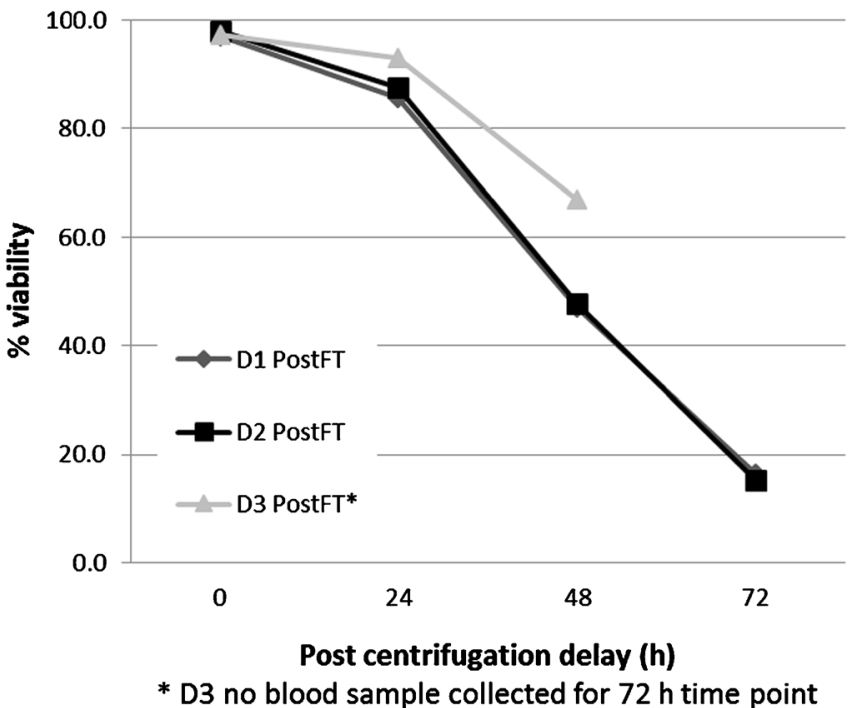

Fig. 2 a-d Impact of CPT heparin blood precentrifugation and post-centrifugation delays on PBMC viability, before and after cryopreservation. D1, D2, D3: donor 1, donor 2, donor 3. PreFT, pre-freeze-thaw. PostFT, post-freeze-thaw 


\section{PBMC Isolation}

Isolation of PBMCs is essential since immune responses are significantly higher when using isolated PBMCs than when using whole blood [26]. Common methods for PBMC isolation include density gradient centrifugation with Ficoll-Paque and isolation with cell preparation tubes, such as CPT, SepMate tubes with Lymphoprep, Leucosep, RosetteSep, and Accuspin ${ }^{\mathrm{TM}}$. The method for PBMC isolation on Ficoll gradient was first described in 1968 [37]. Comparison of PBMCs isolated using standard Ficoll vs SepMate tubes showed equivalent performance in recovery, viability, leukocyte and CD4+ memory subset frequencies, and T cell function by IFN- $\gamma$ ELISPOT [38] (Fig. 3). A summary of the isolation methods most commonly used is shown in Table 1.

An erythrocyte lysis technique may be a critical step in the isolation procedure, depending on the required purity and downstream application. Erythrocyte lysis can be achieved with ammonium chloride, with a lysing reagent containing a fixative or with other commercial lysis solutions. Immature erythroid nucleated cells may be resistant to this lysis. In certain indications, such as in alcoholic patients, complete erythrocyte lysis may be difficult to achieve (Betsou, IBBL, unpublished).

The effect of density gradient reagent, washing buffer composition and centrifugal speed that is applied during the isolation of mononuclear cells on recovery, and migration and clonogenicity functional properties has been studied [39]. In these studies, the importance of centrifugal force and albumin supplementation in the washing buffer has been shown. Furthermore, we have shown that the brand of the centrifuge has a tremendous impact on the cell recovery of PBMCs isolated with the Sepmate method. More specifically, NuAire NUWIND NU-C200R-E centrifuges allow us to recover three to five times more PBMCs than Thermo SL 40R centrifuges, using the same centrifuge acceleration and braking values. The difference in PBMC yield was not observed with Ficoll density gradient (Sokolowska, IBBL, unpublished).
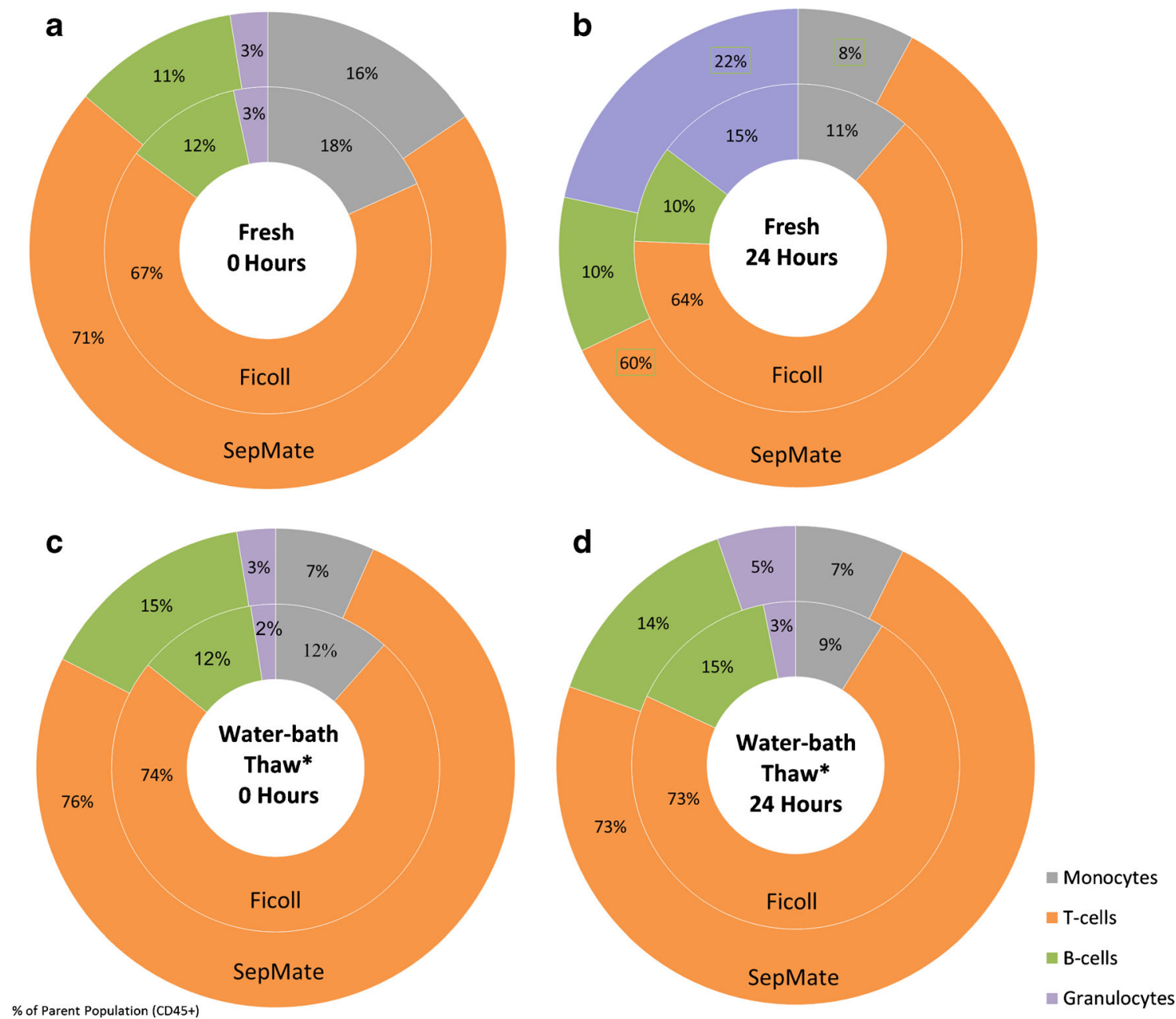

Fig. 3 Comparison of a leukocyte subset frequencies and $\mathbf{b}$ CD4+ T cell subset frequencies, calculated as a percentage of CD45+ cells, of PBMCs isolated by Ficoll and SepMate methods measured by flow cytometry.

There was no significant difference between subset frequencies when comparing both methods $(p>0.05)$. A, B: freshly isolated PBMC $(n=$ 6). C, D: cryopreserved PBMC $(n=3)$ 


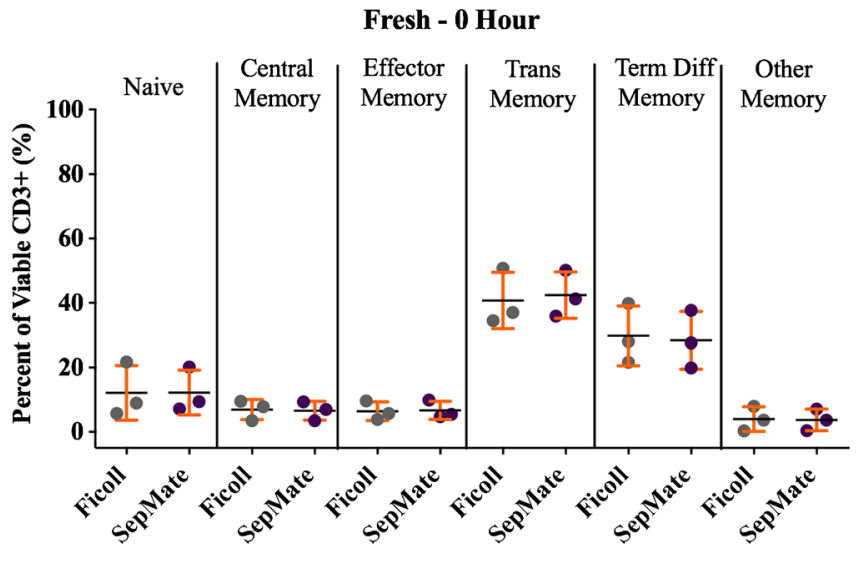

Cryopreserved - 0 Hour

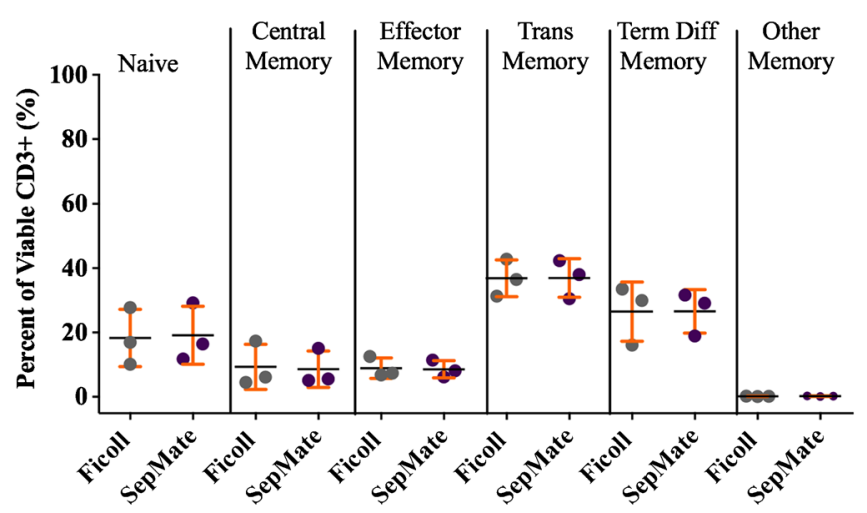

Fig. 3 (continued)

Isolation by cell separation tubes requires less skill than isolation with Ficoll gradient, and is compatible with automation [40]. CPT, Accuspin, and Ficoll isolation methods have shown similar performance on PBMC recovery and viability [17]. In addition, CPT has shown equivalent performance to Ficoll when comparing recovery, viability, and IFN- $\gamma$

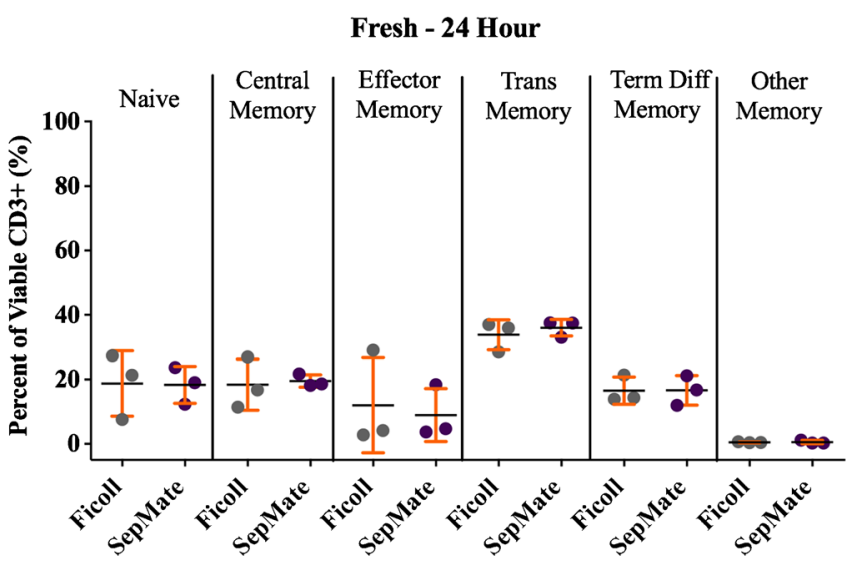

Cryopreserved - 24 Hour

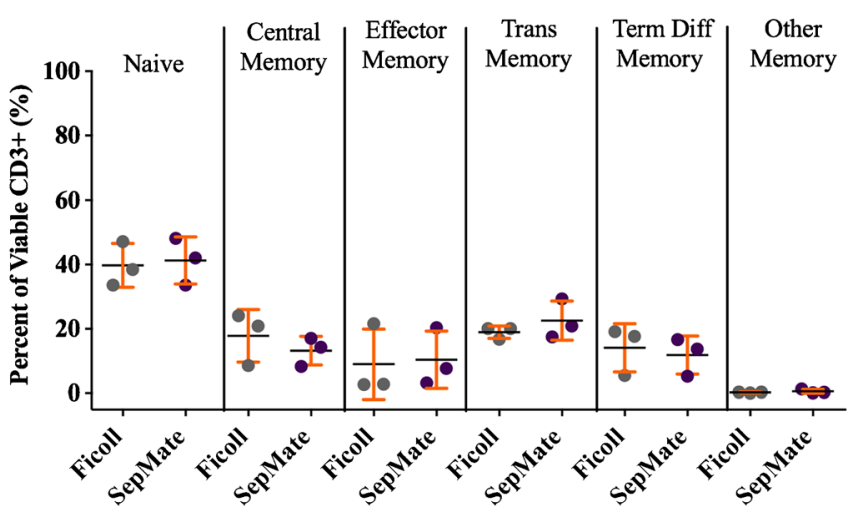

expression in cryopreserved CD8+ and CD8- cells [41] or when comparing subsequent recovery and purity of immune cell subsets and associated gene expression profiles [42]. In a more recent study, CPT-isolated PBMCs gave higher overall cytokine responses than SepMate/Lymphoprep- and Ficollisolated cells, and similar viability and $\mathrm{LDH}$ release in $\mathrm{LDH}$

Table 1 Summary of the commonly used PBMC isolation methods

\begin{tabular}{|c|c|c|c|}
\hline PBMC separation method & Brand and supplier & Advantage & Disadvantage \\
\hline $\begin{array}{l}\text { Density gradient centrifugation } \\
\text { (DGC) without barrier }\end{array}$ & $\begin{array}{l}\text { Ficoll (GE), Lymphoprep } \\
\text { (STEMCELL Technologies), } \\
\text { Histopaque (Sigma-Aldrich) }\end{array}$ & $\begin{array}{l}\text { Inexpensive } \\
\text { Gold standard } \\
\text { Flexible volume } \\
\text { Low RBC contamination }\end{array}$ & $\begin{array}{l}\text { Laborious sample loading } \\
\text { and PBMC collection } \\
\text { Operator bias }\end{array}$ \\
\hline DGC with disc barrier & $\begin{array}{l}\text { Leucosep (Greiner Bio-One), } \\
\text { SepMate (STEMCELL } \\
\text { Technologies), Accusep (Sigma) }\end{array}$ & $\begin{array}{l}\text { Quick procedure } \\
\text { Simple blood loading and PBMC } \\
\text { collection } \\
\text { Possibly prefilled with lymphocyte } \\
\text { separation medium }\end{array}$ & $\begin{array}{l}\text { More expensive than DGC } \\
\text { More RBC contamination } \\
\text { than DGC }\end{array}$ \\
\hline DGC with gel barrier & CPT (BD) & $\begin{array}{l}\text { Quickest procedure } \\
\text { Blood collection and PBMC } \\
\text { isolation in single tube }\end{array}$ & $\begin{array}{l}\text { Larger tube size } \\
\text { Expensive } \\
\text { Risk of glass tube } \\
\quad \text { collapse during centrifugation }\end{array}$ \\
\hline $\begin{array}{l}\text { DGC with antibody-driven } \\
\text { negative depletion }\end{array}$ & $\begin{array}{l}\text { RossetteSep (STEMCELL } \\
\text { Technologies) }\end{array}$ & $\begin{array}{l}\text { Depletion of specific PBMC } \\
\text { subpopulations either with } \\
\text { or without disc barrier }\end{array}$ & More expensive \\
\hline
\end{tabular}


cytotoxicity assay [43]. In conclusion, the CPT method is simple and fit-for-purpose for the isolation of high-quality immune cell subpopulations.

\section{Immunomagnetic Bead-Based Cell Sorting}

Magnetic sorting of PBMCs and subpopulations for purification or enrichment purposes is based on antibody-conjugated microbeads, which bind either to the cells of interest (positive sorting) or to all other cell subpopulations, except the cells of interest (negative sorting). The microbeads are designed to be non-toxic, to be biodegradable, and to not affect the activation status of the cells. However, it has been shown that positively sorted CD14+ monocytes, as opposed to negatively sorted ones, exhibit reduced activation and proliferation capacity after stimulation with LPS [44]. Similarly, positively sorted CD4+ and CD8+ T cells may undergo activation by ligation of CD4 and CD8 molecules, while cell-sorting procedures appear to have no effect on expression of cell surface molecules, such as interleukin2 receptor (IL-2R, CD25) [45]. Magnetic bead sorting may thus introduce a bias in downstream analyses due to either activation of cells or interference with immunofluorescent staining.

\section{Cryopreservation}

Freshly isolated cells are optimal for many downstream applications; however, cryopreservation allows batching for downstream assays and analysis according to a predefined experimental plan, and thus reduces collection center-related and analytical run-related bias and allows analysis of sequential samples from the same patient isochronously. The purpose of most of the biospecimen research work done in this area has been to compare different PBMC quality attributes before (pre-freeze) and after (post-thaw) cryopreservation.

Cryopreservation of whole blood instead of isolated PBMCs has been attempted. Although viable B cell sorting and EBV transformation can be successfully performed [46, 47], the cells suffer from significant deterioration in terms of viability, apoptosis, and EBV transformability [11].

The fitness-for-purpose of PBMC cryopreservation has been demonstrated in the scope of preservation of lymphocyte immunophenotypes and proliferative responses [48, 49], pyrogenic responses [50, 51], establishment of LCLs [52], Th1/Th2 cytokine ratio after stimulation [53], T cell culture and subsequent polyfunctional antigen-specific CD4 and CD8 T cell responses $[16,54]$, host cell reactivation (HCR) assay [55], and mutagen sensitivity assay for assessment of DNA repair capacity [56]. Cryopreservation does not induce any significant difference in the proportions of $\mathrm{T}$ cells expressing CD3 and monocytes/ macrophages expressing CD14 [57]. The impact of cryopreservation on B cells expressing CD19, if it exists, is small [48].

Contradictory conclusions have been published concerning the impact of cryopreservation on the adhesion-mediated interactions between mononuclear and endothelial cells. Cryopreservation does not alter integrins on the mononuclear cells and hence does not affect rolling and adhesion on TNF- $\alpha$-activated endothelial cells [57]. Another study found a change in the adhesive phenotype and a modulation of the ability of monocytes to migrate across endothelial monolayers when cells were tested immediately post-thaw, but not if they were allowed to recover before testing [58]. Cryopreservation may induce a decrease in intracellular calcium that is necessary for polymerization of cytoskeletal proteins and thus hamper the motility of the cells [59].

Although cryopreserved PBMCs are suitable for all the above applications, a certain bias can be induced by the cryopreservation process. Cryopreserved cells are more sensitive to $\gamma$ irradiation [56]. Others have shown a significant decrease of CD62L expression in cryopreserved PBMCs, leading to a decrease of the relative proportions of naïve (CD45RA+ $\mathrm{CD} 62 \mathrm{~L}+)$ and central memory (CD45RO+ CD62L+) T cells, an increase of the relative proportions of effector $\mathrm{CD} 8+\mathrm{T}$ cells, and a loss of proliferative responses to certain antigens [60]. The relative sensitivity of the CD45RO and CD62L markers to cryopreservation was confirmed by Weinberg et al.; these were the only two markers that showed a median $\%$ difference between fresh and cryopreserved PMBCs of around $10 \%$, with all other markers studied showing $\%$ differences of $1-6 \%$ [13]. Reduced recovery of colonyforming unit-granulocyte-macrophage CD34+ cells has been reported after cryopreservation [61], as well as a small reduction in HLA-DR+ CD38+ and CD45RA+ CD62L+ T cells [48]. Furthermore, a decrease in the relative proportion of regulatory T cells (CD4+ CD25+ FoxP3+) has been shown [62]. Contrary to the above studies, Van Hemelen et al., using an optimized cryopreservation protocol (optimal cell concentration, freezing medium composition, use of progressive rate freezer, optimal thawing protocol by gradually adding warm culture media in the cryopreserved cells), demonstrated that cryopreservation does not alter the frequency of regulatory $\mathrm{T}$ cells [63].

When cryopreservation induces a reduction in some lymphocyte immunophenotypes or some proliferative responses, this bias can be made systematic, through standardization of the critical cryopreservation parameters. These are described below.

The cryopreservation protocol applied, in terms of the composition and temperature of the cryopreservation medium, progressive rate freezing program, and cell concentration, is a critical factor. The composition of the cryomedium (e.g., the specific serum additive) has a significant impact on viability and apoptosis, with a beneficial effect of the presence of apoptosis inhibitors $[64,65]$. The temperature of the cryopreservation medium at the time it is being added to the cells has a significant impact on the frequency and type of cytokine signatures [49, 66].

The progressive rate freezing program may be critical for sensitive cell types: use of a controlled rate freezer leads to higher yields of dendritic cells and to higher autologous T cell stimulation [67] than freezing with isopropanol. The long-term storage time and temperature of the frozen cells is another 
critical factor. Recovery and viability has been confirmed after 12 years of storage in LN [68], but IFN- $\gamma$ T cell responses may be affected by long-term storage in $\mathrm{LN}$, in an antigen-specific manner [69]. Storage at $-30^{\circ} \mathrm{C}$ and $-70^{\circ} \mathrm{C}$ induces significant apoptosis [11], while gene expression profiles are affected by long-term storage at $-80^{\circ} \mathrm{C}$ when compared to LN [70]. Temperature cycling from below -130 to $-60{ }^{\circ} \mathrm{C}$ significantly affected functionality, as assessed by ELISPOT [71]. The shipment temperature may have an impact on viability, proliferative responses to antigenic stimulations, and ICS results, with detrimental effects of temperature fluctuations between LN and $-80{ }^{\circ} \mathrm{C}$ and of $-20{ }^{\circ} \mathrm{C}$ temperatures $[14,17]$.

The thawing step is critical. Slow dilution of the freshly thawed PBMCs by dropwise addition of culture media as well as overnight recovery is important for optimal proliferative responses [13]. Methods for automated cryovial thawing have been developed such as BioCision ThawSTAR, and help ensure standardized sterile and reproducible cell recovery after cryopreservation [38] (Fig. 4).

Efficient washing in isotonic buffer is important in order to remove impurities, especially if staining with lectins is intended, since lectins may bind to residual sugars in the medium. The temperature of the washing medium is also important, with higher viability observed when using prewarmed washing medium [64].

If cryopreservation induces a loss of activity, this makes it unfit for the purpose. In this respect, two studies have shown that cryopreservation has a detrimental effect on myeloidderived suppressor cells (MDSCs). MDSCs are cells that cosediment with the PBMCs. Cryopreservation may lead to reduced frequencies of MDSCs [72]. It might induce a loss of suppressor activity, measured by carboxyfluorescein diacetate succinimidyl ester (CFSE)-based suppression assay, arginase I

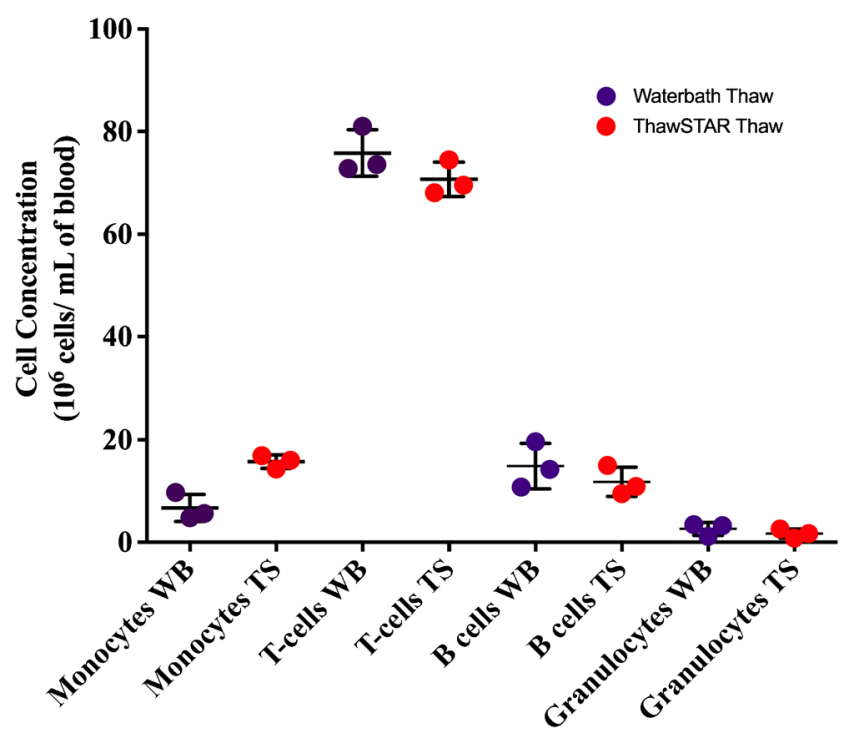

Fig. 4 Comparison of leukocyte subset frequencies as measured by flow cytometry in PBMCs thawed in a $37^{\circ} \mathrm{C}$ water bath (WB) and a Biocision ThawSTAR (TS) expression, or reactive oxygen species (ROS) upregulation in certain subsets of MDSCs [73]. However, in this study, the freezing protocol applied was suboptimal: the concentration of cells was too high, the DMSO concentration in the cryopreservation medium was high, freezing was not progressive, and the cells were stored at $-80^{\circ} \mathrm{C}$ instead of liquid nitrogen (LN). Of note, DMSO is toxic to cells, and protocols to reduce DMSO from the standard $10 \%$ to $5 \%$ have shown increased CD4+ T cell function after cryopreservation [74•].

The optimal concentration of cells for cryopreservation is $1-5 \times 10^{6}$ cells $/ \mathrm{ml}$. New devices have recently been commercialized for standardized freezing (Coolcell device) and for standardized thawing of the cells (Biocision ThawStar Cell thawing platform). The post-thaw viability of PBMCs frozen with a Coolcell device is similar to that of PBMCs frozen with a Mr Frosty device (Lambert, IBBL, unpublished).

\section{Conclusion}

Isolated PBMCs are used in preclinical research as a source of biomarkers in infectious and chronic diseases (e.g., isletautoreactive $\mathrm{T}$ cells in type 1 diabetes), but also in epidemiological studies [75], vaccine trials ( $\mathrm{T}$ cell responses as correlates of immunity), or clinical trials (monitoring of cellular immune functions during immunotherapies). Although this article does not focus on cell therapy, there are several therapeutic applications, based on T cells (CAR T cells, antiviral T cells after bone marrow transplantation, Treg cells for graftversus-host disease) or on ex vivo manipulation of dendritic cells for reinfusion into cancer patients. The availability of large quantities of functionally effective dendritic cells is critical in this context. Preanalytics and cryopreservation are also of importance in the cell therapy field [76].

It is important that the isolation method is simple and the output PBMCs are non-activated, non-contaminated by other cell types (RBCs, granulocytes) and of high viability. A series of basic protocols for the collection, storage, and preparation of human blood cells has recently been published by the National Heart, Lung, and Blood Institute [77]. But the devil is in the details. For example, the details of the processing method used to generate DCs from monocytes may have an impact on the phenotypic and functional characteristics of the DCs. It has been suggested that monocyte isolation through flask adherence or magnetic sorting may influence the yield, viability, and cytokine release of the generated DCs [78].

Participation of PBMC processing laboratories in external quality assurance programs (EQA) is the only way to benchmark the performance of the laboratory. The benefits of participating in such programs have been demonstrated [79], although implementation of such a program requires optimization of the shipment conditions [80]. 
In conclusion, analysis of PBMC functional attributes requires standardization of the anticoagulant and blood collection tube type used, proper filling of the blood tubes, minimizing delay between blood collection and processing, and validation of the PBMC isolation protocol (centrifuge brand and settings, separation medium, buffer composition), the cryopreservation protocol (cryopreservation medium, device), the thawing protocol, and the post-thaw recovery. All of the above must be carefully considered on a case-by-case basis, depending on the specific goals of the study and the functional applications that are being investigated. When the purpose of PBMC production is a proliferation assay, it is important to validate the processing method in the particular context of use, with the anticoagulant, the cell type, and each particular antigen of interest, in the presence or absence of disease [81]. When the purpose of PBMC production is the use of multiplex antibody panels for cell surface and intracellular markers, such as markers of naïve/memory CD4, CD8, Treg activation, exhaustion, or senescence, it is important to validate the PBMC processing method and confirm that cytometric separation and intensity of the markers of interest pass predefined acceptance criteria. Systematic errors linked to shipment and/or cryopreservation can be accounted for once they are known and constant. PBMC biospecimen research should be supported by funding bodies in order to increase the reproducibility and robustness of the outputs of research based on PBMC functional assays.

Acknowledgments We are grateful to Pauline Lambert and Kate Sokolowska for excellent work on some PBMC preanalytical aspects.

\section{Compliance with Ethical Standards}

Conflict of Interest The authors declare that they have no conflict of interest.

Human and Animal Rights and Informed Consent The data presented and based on unpublished work by the authors, have been obtained in studies with ethics committee approval.

Open Access This article is distributed under the terms of the Creative Commons Attribution 4.0 International License (http:// creativecommons.org/licenses/by/4.0/), which permits unrestricted use, distribution, and reproduction in any medium, provided you give appropriate credit to the original author(s) and the source, provide a link to the Creative Commons license, and indicate if changes were made.

\section{References}

Papers of particular interest, published recently, have been highlighted as:

\section{- Of importance}

1. Pattengale P, Smith R, Gerber P. Selective transformation of B lymphocytes by EB virus. Lancet. 1973;302(7820):93-4.

2. Baeyens A, Thierens H, Vandenbulcke K, De Ridder L, Vral A. The use of EBV-transformed cell lines of breast cancer patients to measure chromosomal radiosensitivity. Mutagenesis. 2004;19(4):285-90.

3. Clarke JJ, Lawlor TE, Madraymootoo W, Pant K, Young RR, Wagner VO III, et al. Summary of in vitro genetic toxicology assay results: expected and unexpected effects of recent study design modifications. Environ Mol Mutagen. 2012;53(8):631-5.

4. Botbol Y, Macian F. Assays for monitoring macroautophagy activity in T cells. Immunosenescence; Springer 2015. p. 143-153.

5. Zigmond S, Lauffenburger D. Assays of leukocyte chemotaxis. Annu Rev Med. 1986;37(1):149-55.

6. Saeko F, Mitoshi A, Michio Y, Toshio S, Kyoko K, Masayuki H, et al. Cryopreservation of human lymphocytes for assessment of lymphocyte subsets and natural killer cytotoxicity. J Immunol Methods. 1986;90(2):265-73.

7. Boks MA, Zwaginga JJ, Van Ham SM, Ten Brinke A. An optimized CFSE-based T-cell suppression assay to evaluate the suppressive capacity of regulatory T-cells induced by human tolerogenic dendritic cells. Scand J Immunol. 2010;72(2):158-68.

8. Chandran PA, Laske K, Cazaly A, Rusch E, Schmid-Horch B, Rammensee HG, et al. Validation of immunomonitoring methods for application in clinical studies: the HLA-peptide multimer staining assay. Cytometry B Clin Cytom. 2018;94(2):342-53.

9. Palma L, Rossetti F, Dominici S, Buondelmonte C, Rocchi MB, Rizzardi GP, et al. Determination of interference during in vitro pyrogen detection: development and characterization of a cellbased assay. Assay Drug Dev Technol. 2017;15(2):64-76.

10. Findlay L, Eastwood D, Stebbings R, Sharp G, Mistry Y, Ball C, et al. Improved in vitro methods to predict the in vivo toxicity in man of therapeutic monoclonal antibodies including TGN1412. J Immunol Methods. 2010;352(1-2):1-12.

11. Fowke KR, Behnke J, Hanson C, Shea K, Cosentino LM. Apoptosis: a method for evaluating the cryopreservation of whole blood and peripheral blood mononuclear cells. J Immunol Methods. 2000;244(1-2):139-44.

12. Weinberg A, Zhang L, Brown D, Erice A, Polsky B, Hirsch MS, et al. Viability and functional activity of cryopreserved mononuclear cells. Clin Diagn Lab Immunol. 2000;7(4):714-6.

13. Weinberg A, Song L-Y, Wilkening C, Sevin A, Blais B, Louzao R, et al. Optimization and limitations of use of cryopreserved peripheral blood mononuclear cells for functional and phenotypic T-cell characterization. Clin Vaccine Immunol. 2009;16(8): 1176-86.

14. Smith JG, Joseph HR, Green T, Field JA, Wooters M, Kaufhold $\mathrm{RM}$, et al. Establishing acceptance criteria for cell-mediatedimmunity assays using frozen peripheral blood mononuclear cells stored under optimal and suboptimal conditions. Clin Vaccine Immunol. 2007;14(5):527-37.

15. Kofanova O, Bellora C, Quesada RA, Bulla A, Linares HN, Lescuyer P, et al. A gene expression assay indicates PBMC quality. J Immunol Methods. 2019;465:13-19. This article describes a novel method to assess preanalytical quality of PBMCs.

16. Lin Y, Gallardo HF, Ku GY, Li H, Manukian G, Rasalan TS, et al. Optimization and validation of a robust human T-cell culture method for monitoring phenotypic and polyfunctional antigen-specific CD4 and CD8 T-cell responses. Cytotherapy. 2009;11(7):912-22.

17. Bull M, Lee D, Stucky J, Chiu Y-L, Rubin A, Horton H, et al. Defining blood processing parameters for optimal detection of cryopreserved antigen-specific responses for HIV vaccine trials. J Immunol Methods. 2007;322(1):57-69.

18. Wang Y-h, Ma F, Fu F, Wei Z, Dong Z, Zhu L et al. Selection of storage time, temperature and anticoagulants of peripheral blood samples for culturing cytokine-induced killer cells. Xi bao yu fen zi mian yi xue za zhi= Chinese journal of cellular and molecular immunology. 2016;32(3):382-6.

19. Son BK, Roberts RL, Ank BJ, Stiehm ER. Effects of anticoagulant, serum, and temperature on the natural killer activity of human 
peripheral blood mononuclear cells stored overnight. Clin Diagn Lab Immunol. 1996;3(3):260-4.

20. Herzogova E, Dankova P. Ethylenediaminetetraacetic acid, sodium citrate, heparin and citrate phosphate dextrose-adenine anticoagulants differentially affect cytokine mRNA expression in blood leukocytes. Clin Lab. 2016;62(7):1371-4.

21. Yokota M, Tatsumi N, Nathalang O, Yamada T, Tsuda I. Effects of heparin on polymerase chain reaction for blood white cells. J Clin Lab Anal. 1999;13(3):133-40.

22. Bai X, Fischer S, Keshavjee S, Liu M. Heparin interference with reverse transcriptase polymerase chain reaction of RNA extracted from lungs after ischemia-reperfusion. Transpl Int. 2000;13(2): $146-50$.

23. Nicholson JK, Green TA, Laboratories C. Selection of anticoagulants for lymphocyte immunophenotyping: effect of specimen age on results. J Immunol Methods. 1993;165(1):31-5.

24. Rundgren IM, Bruserud Ø, Ryningen A, Ersvær E. Standardization of sampling and sample preparation for analysis of human monocyte subsets in peripheral blood. J Immunol Methods. 2018;461: 53-62. This is an important study on the impact of anticoagulants.

25. Ibeagha-Awemu EM, Ibeagha AE, Zhao X. The influence of different anticoagulants and sample preparation methods on measurement of mCD14 on bovine monocytes and polymorphonuclear neutrophil leukocytes. BMC Res Notes. 2012;5(1):93.

26. Weinberg A, Betensky RA, Zhang L, Ray G. Effect of shipment, storage, anticoagulant, and cell separation on lymphocyte proliferation assays for human immunodeficiency virus-infected patients. Clin Diagn Lab Immunol. 1998;5(6):804-7.

27. Glassberg J, Rahman AH, Zafar M, Cromwell C, Punzalan A, Badimon JJ, et al. Application of phospho-CyTOF to characterize immune activation in patients with sickle cell disease in an ex vivo model of thrombosis. J Immunol Methods. 2018;453:11-9. This is a methodological study on CyTOF PBMC analyses.

28. Saxton JM, Pockley AG. Effect of ex vivo storage on human peripheral blood neutrophil expression of $\mathrm{CD} 11 \mathrm{~b}$ and the stabilizing effects of Cyto-Chex ${ }^{\mathrm{TM}}$. J Immunol Methods. 1998;214(1-2):11-7.

29. McKenna KC, Beatty KM, Miguel RV, Bilonick RA. Delayed processing of blood increases the frequency of activated CD11b+ CD15+ granulocytes which inhibit T cell function. J Immunol Methods. 2009;341(1):68-75.

30. Schmielau J, Finn OJ. Activated granulocytes and granulocytederived hydrogen peroxide are the underlying mechanism of suppression of t-cell function in advanced cancer patients. Cancer Res. 2001;61(12):4756-60.

31. Bouwman J, Thijsen S, Bossink A. Improving the timeframe between blood collection and interferon gamma release assay using TCell Xtend®. J Infect. 2012;64(2):197-203.

32. Betensky RA, Connick E, Devers J, Landay AL, Nokta M, Plaeger $\mathrm{S}$, et al. Shipment impairs lymphocyte proliferative responses to microbial antigens. Clin Diagn Lab Immunol. 2000;7(5):759-63.

33. Palmirotta R, De Marchis ML, Ludovici G, Leone B, Savonarola A, Ialongo $\mathrm{C}$, et al. Impact of preanalytical handling and timing for peripheral blood mononuclear cells isolation and RNA studies: the experience of the Interinstitutional Multidisciplinary BioBank (BioBIM). Int J Biol Markers. 2012;27(2):90-8.

34. Olson WC, Smolkin ME, Farris EM, Fink RJ, Czarkowski AR, Fink JH, et al. Shipping blood to a central laboratory in multicenter clinical trials: effect of ambient temperature on specimen temperature, and effects of temperature on mononuclear cell yield, viability and immunologic function. J Transl Med. 2011;9(1):26.

35. Naranbhai V, Bartman P, Ndlovu D, Ramkalawon P, Ndung'u T, Wilson D, et al. Impact of blood processing variations on natural killer cell frequency, activation, chemokine receptor expression and function. J Immunol Methods. 2011;366(1-2):28-35.
36. Kim D-W, Jang Y-Y, Shin M-G, Shin J-H, Suh S-P, Ryang D-W, et al. Overnight storage of blood in ACD tubes at $4 \mathrm{C}$ increases NK cell fraction in peripheral blood mononuclear cells. Ann Clin Lab Sci. 2013;43(3):267-73.

37. Boyum A. Separation of leukocytes from blood and bone marrow. Scand J Clin Lab Invest. 1968;21:77.

38. Stone M, Murcia K, Dimapasoc M, Yip B, Thompson M, Kunkel EJ, et al. Maximizing PMBC recovery and viability: a method to optimize and streamline peripheral blood mononuclear cell isolation, cryopreservation, and thawing. Bioprocess Int. 2015.

39. van Beem RT, Hirsch A, Lommerse IM, Zwaginga JJ, Noort WA, Biemond BJ, et al. Recovery and functional activity of mononuclear bone marrow and peripheral blood cells after different cell isolation protocols used in clinical trials for cell therapy after acute myocardial infarction. EuroIntervention. 2008;4(1):133-8.

40. Hamot G, Ammerlaan W, Mathay C, Kofanova O, Betsou F. Method validation for automated isolation of viable peripheral blood mononuclear cells. Biopreserv Biobanking. 2015;13(3): 152-63.

41. Ruitenberg JJ, Mulder CB, Maino VC, Landay AL, Ghanekar SA. VACUTAINER ${ }^{\circledR}$ CPT ${ }^{\mathrm{TM}}$ and Ficoll density gradient separation perform equivalently in maintaining the quality and function of PBMC from HIV seropositive blood samples. BMC Immunol. 2006;7(1):11.

42. Corkum CP, Ings DP, Burgess C, Karwowska S, Kroll W, Michalak TI. Immune cell subsets and their gene expression profiles from human PBMC isolated by Vacutainer Cell Preparation Tube $\left(\mathrm{CPT}^{\mathrm{TM}}\right)$ and standard density gradient. BMC Immunol. 2015;16(1):48.

43. Grievink HW, Luisman T, Kluft C, Moerland M, Malone KE. Comparison of three isolation techniques for human peripheral blood mononuclear cells: cell recovery and viability, population composition, and cell functionality. Biopreserv Biobanking. 2016;14(5):410-5.

44. Bhattacharjee J, Das B, Mishra A, Sahay P, Upadhyay P. Monocytes isolated by positive and negative magnetic sorting techniques show different molecular characteristics and immunophenotypic behaviour. F1000Research. 2017;6.

45. Stanciu LA, Shute J, Holgate ST, Djukanović R. Production of IL-8 and IL- 4 by positively and negatively selected CD4+ and CD8+ human T cells following a four-step cell separation method including magnetic cell sorting (MACS). J Immunol Methods. 1996;189(1):107-15.

46. Bernacki SH, Stankovic AK, Williams LO, Beck JC, Herndon JE, Snow-Bailey K, et al. Establishment of stably EBV-transformed cell lines from residual clinical blood samples for use in performance evaluation and quality assurance in molecular genetic testing. J Mol Diagn. 2003;5(4):227-30.

47. Amoli M, Carthy D, Platt H, Ollier W. EBV Immortalization of human B lymphocytes separated from small volumes of cryopreserved whole blood. Int J Epidemiol. 2008;37(suppl_1): i41-i5.

48. Reimann KA, Chernoff M, Wilkening CL, Nickerson CE, Landay AL. Preservation of lymphocyte immunophenotype and proliferative responses in cryopreserved peripheral blood mononuclear cells from human immunodeficiency virus type 1-infected donors: implications for multicenter clinical trials. Clin Diagn Lab Immunol. 2000;7(3):352-9.

49. Kreher CR, Dittrich MT, Guerkov R, Boehm BO, Tary-Lehmann M. CD4+ and CD8+ cells in cryopreserved human PBMC maintain full functionality in cytokine ELISPOT assays. J Immunol Methods. 2003;278(1-2):79-93.

50. Koryakina A, Frey E, Bruegger P. Cryopreservation of human monocytes for pharmacopeial monocyte activation test. J Immunol Methods. 2014;405:181-91. 
51. Solati S, Aarden L, Zeerleder S, Wouters D. An improved monocyte activation test using cryopreserved pooled human mononuclear cells. Innate Immun. 2015;21(7):677-84.

52. Tremblay S, Khandjian EW. Successful use of long-term frozen lymphocytes for the establishment of lymphoblastoid cell lines. Clin Biochem. 1998;31(7):555-6.

53. Kilani RT, Delehanty M, Shankowsky HA, Ghahary A, Scott P, Tredget EE. Fluorescent-activated cell-sorting analysis of intracellular interferon- $\gamma$ and interleukin- 4 in fresh and frozen human peripheral blood T-helper cells. Wound Repair Regen. 2005;13(4): 441-9.

54. Wang S-Y, Hsu M-L, Tzeng C-H, Hsu H-C, Ho C-K. The influence of cryopreservation on cytokine production by human $\mathrm{T}$ lymphocytes. Cryobiology. 1998;37(1):22-9.

55. Athas WF, Hedayati MA, Matanoski GM, Farmer ER, Grossman L. Development and field-test validation of an assay for DNA repair in circulating human lymphocytes. Cancer Res. 1991;51(21):5786-93.

56. Cheng L, Wang L, Spitz M, Wei Q. Cryopreserving whole blood for functional assays using viable lymphocytes in molecular epidemiology studies. Cancer Lett. 2001;166(2):155-63.

57. Lockmann A, Schön MP. Phenotypic and functional traits of peripheral blood mononuclear cells retained by controlled cryopreservation: implications for reliable sequential studies of dynamic interactions with endothelial cells. Exp Dermatol. 2013;22(5):358-9.

58. Faint JM, Tuncer C, Garg A, Adams DH, Lalor PF. Functional consequences of human lymphocyte cryopreservation: implications for subsequent interactions of cells with endothelium. J Immunother. 2011;34(8):588-96.

59. Koch E, Larak M, Ellendorff F. Comparative studies on in vitro reactivity of fresh and cryopreserved pig lymphocytes. Cryobiology. 1991;28(5):405-12.

60. Costantini A, Mancini S, Giuliodoro S, Butini L, Regnery C, Silvestri G, et al. Effects of cryopreservation on lymphocyte immunophenotype and function. J Immunol Methods. 2003;278(1-2):145-55.

61. Majado MJ, Salgado-Cecilia G, Blanquer M, Funes C, GonzálezGarcía C, Insausti CL, et al. Cryopreservation impact on blood progenitor cells: influence of diagnoses, mobilization treatments, and cell concentration. Transfusion. 2011;51(4):799-807.

62. Elkord E. Frequency of human T regulatory cells in peripheral blood is significantly reduced by cryopreservation. J Immunol Methods. 2009;347(1-2):87-90.

63. Van Hemelen D, Elberink JO, Heimweg J, van Oosterhout A, Nawijn M. Cryopreservation does not alter the frequency of regulatory $\mathrm{T}$ cells in peripheral blood mononuclear cells. J Immunol Methods. 2010;353(1-2):138-40.

64. Disis ML, dela Rosa C, Goodell V, Kuan L-Y, Chang JC, KuusReichel K, et al. Maximizing the retention of antigen specific lymphocyte function after cryopreservation. J Immunol Methods. 2006;308(1-2):13-8.

65. Cosentino L, Corwin W, Baust J, Diaz-Mayoral N, Cooley H, Shao W, et al. Preliminary report: evaluation of storage conditions and cryococktails during peripheral blood mononuclear cell cryopreservation. Cell Preserv Technol. 2007;5(4):189-204.

66. Tree TI, Roep BO, Peakman M. Enhancing the sensitivity of assays to detect T cell reactivity: the effect of cell separation and cryopreservation media. Ann N Y Acad Sci. 2004;1037(1):26-32.

67. Buhl T, Legler TJ, Rosenberger A, Schardt A, Schön MP, Haenssle HA. Controlled-rate freezer cryopreservation of highly concentrated peripheral blood mononuclear cells results in higher cell yields and superior autologous T-cell stimulation for dendritic cell-based immunotherapy. Cancer Immunol Immunother. 2012;61(11):2021-31.

68. Kleeberger CA, Lyles RH, Margolick JB, Rinaldo CR, Phair JP, Giorgi JV. Viability and recovery of peripheral blood mononuclear cells cryopreserved for up to 12 years in a multicenter study. Clin Diagn Lab Immunol. 1999;6(1):14-9.

69. Owen RE, Sinclair E, Emu B, Heitman JW, Hirschkorn DF, Epling $\mathrm{CL}$, et al. Loss of $\mathrm{T}$ cell responses following long-term cryopreservation. J Immunol Methods. 2007;326(1-2):93-115.

70. Yang J, Diaz N, Adelsberger J, Zhou X, Stevens R, Rupert A, et al. The effects of storage temperature on PBMC gene expression. BMC Immunol. 2016;17(1):6.

71. Angel S, von Briesen H, Oh Y-J, Baller MK, Zimmermann H, Germann A. Toward optimal cryopreservation and storage for achievement of high cell recovery and maintenance of cell viability and $\mathrm{T}$ cell functionality. Biopreserv Biobanking. 2016;14(6):539-47.

72. Trellakis S, Bruderek K, Hütte J, Elian M, Hoffmann TK, Lang S, et al. Granulocytic myeloid-derived suppressor cells are cryosensitive and their frequency does not correlate with serum concentrations of colony-stimulating factors in head and neck cancer. Innate Immun. 2013;19(3):328-36.

73. Kotsakis A, Harasymczuk M, Schilling B, Georgoulias V, Argiris A, Whiteside TL. Myeloid-derived suppressor cell measurements in fresh and cryopreserved blood samples. J Immunol Methods. 2012;381(1-2):14-22.

74. Worsham DN, Reems JA, Szczepiorkowski ZM, McKenna DH, Leemhuis T, Mathew AJ, et al. Clinical methods of cryopreservation for donor lymphocyte infusions vary in their ability to preserve functional T-cell subpopulations. Transfusion. 2017;57(6):1555-65. This study focuses on the impact of cryopreservation conditions.

75. Bonassi S, Hagmar L, Strömberg U, Montagud AH, Tinnerberg H, Forni A, et al. Chromosomal aberrations in lymphocytes predict human cancer independently of exposure to carcinogens. Cancer Res. 2000;60(6):1619-25.

76. Suhoski Davis MM, McKenna DH, Norris PJ. How do i participate in T-cell immunotherapy? Transfusion. 2017;57(5):1115-21.

77. Dagur PK, McCoy JP Jr. Collection, storage, and preparation of human blood cells. Curr Protoc Cytom. 2015;73(1):5.1. -5.1. 16.

78. Delirezh N, Shojaeefar E. Phenotypic and functional comparison between flask adherent and magnetic activated cell sorted monocytes derived dendritic cells. Iranian J Immunol. 2012;9(2):98-108.

79. Dyer WB, Pett SL, Sullivan JS, Emery S, Cooper DA, Kelleher $\mathrm{AD}$, et al. Substantial improvements in performance indicators achieved in a peripheral blood mononuclear cell cryopreservation quality assurance program using single donor samples. Clin Vaccine Immunol. 2007;14(1):52-9.

80. Kofanova OA, Davis K, Glazer B, De Souza Y, Kessler J, Betsou F, et al. Viable mononuclear cell stability study for implementation in a proficiency testing program: impact of shipment conditions. Biopreserv Biobanking. 2014;12(3):206-16.

81. Shalekoff S, Page-Shipp L, Tiemessen CT. Effects of anticoagulants and temperature on expression of activation markers CD11b and HLA-DR on human leukocytes. Clin Diagn Lab Immunol. 1998;5(5):695-702.

Publisher's Note Springer Nature remains neutral with regard to jurisdictional claims in published maps and institutional affiliations. 